VI.

\title{
A Case of Tubal Gestation with Acute Salpingitis.*
}

By Thomas Watrs Eden, M.D., Assistant Obstetric Physician, Charing Cross Hospital; Physician to In-patients, Chelsea Hospital for Women, and Queen Charlotte's Lying-in Hospital.

The patient was a married woman, 28 years of age, who had previously had three children, the youngest of which was born on May 20th, 1905. Iler obstetric history presented nothing of importance. In 1900 she underwent an operation for appendicitis. After tha birth of her last child she was in good health up to the month of December, when she was still suckling the child, and there had been no return of menstruation. A little before Christmas 1905, she began to suffer from severe abdominal pain, and in consequence she went to consult a medical practitioner, whom her husband described to me as " almost, if not quite, a specialist." He diagnosed a displacement of the uterus, and regarded this as the cause of the pain. After unsuccessfully attempting to replace the uterus, he decided to treat her with cotton wool plugs, and for several weeks she went to him from time to time for this and some other form of local treatment, the nature of which she did not exactly know. The pain, however, continued unrelieved, and on January 20th, 1906, hæmorrhage set in, which she naturally regarded as a monthly period. After this had continued for 14 days, she decided to wean her baby, and a few days later, she again saw the medical practitioner referred to, who now said that "it was a miscarriage." In spite of local treatment, the hæmorrhage and pain continued unchecked. She could not recollect that anything in the nature of a membrane had been passed. On February 22nd, at one of her visits to her doctor, he again attempted to replace the uterus, using, she says, an instrument for the purpose. This procedure caused her great pain and free bleeding, which lasted for 24 hours. On February 24th she again returned to him, and again an instrument was used to replace the uterus. The result of this was that the patient became extremely ill with acute pain and faintness, and was unable to leave the examination couch for several hours. On reaching home she went to bed and sent for the local doctor who had attended her in confinement, and on the following morning I saw her in consultation with this gentleman.

I found the patient to be a delicate looking, anæmic woman, with pinched features and an anxious expression. Her pulse rate was 110,

- Presented to the Obstetrical Society of London, October 3rd, 1906. 
and her temperature (10 a.m.) was normal : the previous evening the temperature had been $102^{\circ} \mathrm{F}$. There was a moderate degree of distention of the lower abdomen, but tenderness and rigidity were so great that deep palpation was impracticable. There was no dulness on percussion. On vaginal examination $I$ found the cervix distinctly softened, and displaced in an upward and forward direction behind the pubes. In the posterior fornix a tense globular swelling could be felt, the size and relations of which could not be determined owing to the great pain caused by the examination. The swelling could, however, be felt to extend upwards above the level of the pelvic brim. It was obviously impossible, at this moment, to make a precise diagnosis, but it appeared probable that the condition was either ectopic pregnancy with a pelvic hæmatocele, or retroversion of the gravid uterus with acute pelvic inflammation. We accordingly decided to keep the patient under observation for a few days to allow her to recover from the severe illness of the previous day, and to watch the progress of the local conditions.

I saw her again on March 3rd. In the interval she had been confined to bed, and her diet restricted to fluid nourishment: occasional doses of morphia had been given on account of the pain, and the bowels had been difficult to move except by enemata. I thought she was distinctly worse than on the first occasion; the tongue was dry, and on the previous night a severe attack of vomiting had occurred. The pulse rate was 100 , and the temperature $102^{\circ} \mathrm{F}$. The abdomen, although more distended, was softer and less tender, so that a detailed examination was practicable. In the lower part of the abdomen, an extensive swelling could be felt on deep palpation; it was most readily felt immediately above the right Poupart's ligament, where its consistence was very firm; from this spot it could be less distinctly traced upwards to the level of the umbilicus, and well across the middle line into the left iliac region. Over the firm area just referred to, the percussion note was dull, over the remainder of the swelling it was sub-resonant. On bimanual examination the position of the cervix was found as already described: the pelvic cavity appeared to be entirely occupied by a large swelling which could be felt posteriorly and in both lateral fornices, and which extended upwards to the level of the umbilicus. Its consistence, generally, was doughy, but in the right fornix it was very hard. The body of the uterus was found lying in front of the swelling and displaced to the left side: it appeared to be only slightly enlarged. Upon these findings, a diagnosis was made of extra-uterine gestation with pelvic hæmatocele; the patient was removed to a nursing home and the operation performed on the following afternoon.

The operation was in some respects a surprise. On opening the abdomen, omentum and coils of small intestine were found closely 
adherent to a large pelvic swelling, the nature of which was only gradually cleared up as the operation proceeded. There was very little free blood in the peritoneal cavity, and the conditions resembled those associated with pelvic suppuration rather than pelvic hæmatocele; at this moment my diagnosis appeared to have been incorrect. The adherent bowel and omentum having been detached, the pelvic swelling was gradually isolated, and its pedicle found to consist of the right broad ligament, the tissues of which were greatly thickened. The pedicle was clamped, the tumour was cut away, and three interlacing ligatures of strong silk were employed to secure the pedicle. The adhesions were all recent and very vascular; there was consequently considerable oozing from the bed of the tumour, but this was almost completely arrested by packing it for a few minutes with dry gauze pads. The left appendages were now examined and found to be unaffected, except for a few insignificant adhesions. Owing to the generally roughened and inflamed condition of the pelvic peritoneum, it was thought advisable to drain, and accordingly a large rubber tube containing a wick of sterile gauze was introduced through the lower angle of the abdominal wound. The patient's condition at the close of the operation gave us some anxiety, or I should have opened the posterior fornix and drained into the vagina; but a few minutes were saved by adopting the abdominal route.

She made an uninterrupted recovery from the operation; the temperature never reached $100^{\circ} \mathrm{F}$; there was no sickness; the tube was removed in 48 hours, and the bowels were moved naturally on the second day. In a little over three weeks she was able to leave the nursing home.

Description of the parts removed.

On the first inspection the parts removed appeared to consist of the acutely inflamed and dilated Fallopian tube with its companion ovary. The specimen was hardened in Kaiserling solution and then cut open by a longitudinal incision. The lumen of the tube was tortuous, and had been divided by the incision in three places. The outer (ampullary) end was dilated and its wall not much thicker than that of the normal tube : this part contained a quantity of fluid blood and an oval piece of solid clot about the size of a pigeon's egg, which was preserved for microscopic examination. In the remainder of its extent the tube showed well marked thickening of its walls, the average thickness being three-quarters of an inch; the lumen was not dilated, but contained dark clotted blood. The outer surface of the tube was covered with tags of torn adhesions, and the ovary was found upon the posterior surface close to the uterine end; it was flattened and embedded in adhesions, but not much enlarged.

On microscopic examination of the clot from the dilated ampullary end, chorionic villi were found, proving the clot to be a tubal mole 
and the case one of tubal pregnancy. Sections of the thickened wall of the tube showed well marked œdema, and round-celled infiltration. The tube was clearly affected by an acute inflammatory process (acute interstitial salpingitis). The greater part of the mucous membrane had been shed, and was replaced by an irregular layer of granulation tissue. There was no sign of either tubal rupture or abortion.

Remarks.

It is rare to find a gravid Fallopian tube showing such extensive inflammatory changes as have been here described. The view that tubal pregnancy might be occasioned by preceding desquamative endosalpingitis, which at one time received support from several distinguished authorities, has now been generally abandoned, ${ }^{*}$ as evidence has been accumulating that in the great majority of cases no anatomical signs of inflammatory processes can be found in a gravid tube. But it is obvious that a tube in which pregnancy has occurred may subsequently become exposed to the ordinary sources of tubal infection, with the result that tubal gestation and salpingitis will be found in company. There can be little doubt that this was the sequence of events in the present case. The patient was a fertile woman who had borne a child 9 months previously, and had been in perfectly good health up to the time of the occurrence of the tubal pregnancy. There is therefore nothing whatever to suggest the antecedent existence of salpingitis.

It is very difficult to believe that an ovum can become implanted upon an acutely inflamed tubal mucous membrane. Yet this view has beenl upheld by a number of German observers, who have gone so far as to maintain that gestation may occur in a suppurating Fallopian tube. An examination of the cases upon which this statement is based shows that very little care has been taken to exclude the possibility of infection having been subsequent to impregnation; from the association of gestation and suppuration it has been too readily assumed that the latter proceded the former. Thus a case is recorded in support of this view by Prochownik, in which tubal pregnancy and gonorrhceal infection occurred after a first coïtus. After operation the mucous membrane of the gravid tube was found to be suppurating, the pus containing gonococci. It is perfectly clear that in this case the gonorrhœal infection could not possibly have been present in the tube at the time the ovum became implanted in

\footnotetext{
- The older view has, however, the support of A. Martin, who, in his most recent publication, says : " Für die grosse Mehrzahl der Beobachtungen aber halten wir daran fest dass infolge vereins gegangener entzündlicher Vorgänge Hindernisse für die Wanderung des Eies in der Tube entstanden sind, welche dessen Einbettung an dieser pathologischen Stelle veranlasst haben." Pathologie und Therapie der Frauenkrankheiten : in vierter Auflage umgearbeitet von A. Martin und P. Jung. Berlin und Wien., 1907, p. 410.-Ed.
} 
in, unless indeed gonorrhoal infection can ascend the genital canal more rapidly than spermatozoa. It is much more likely that the infection reached the tube at a later date, and in the usual manner, by continuous spread along the mucous membrane.

In the present case no pus was found in the tube, and the source of the infection cannot be definitely determined. Infection from the uterus, set up by the manipulations which were practised in the attempt to replace the uterus, appears to be the most probable explanation.

The chief lesson of the case is to emphasize the importance, in any doubtful case, of giving the most careful consideration to the differential diagnosis of retroversion of the gravid uterus and pelvic hæmatocele. 